erroneously described as true epilepsy. There was slight paralysis of the lower extremities, but this was not always easy to recognise, as he walked lamely in consequence of osteoma of the distal end of the femur. On the 6th of June he had one of the fainting attacks which are not infrequently seen in some forms of brain-softening, and which, except for their longer duration, bear so close a resemblance to the petit mal form of epilepsy. He soon recovered from thisrecovered at least as far as his usual amount of consciousness and mental power was concerned; but there was perhaps a slight increase of the hemiplegia, thus confirming the opinion that the case was one of brain-softening. On the 14th, a similar attack occurred, but instead of rallying he became much worse on the second day-could not move his limbs nor speak, and it was difficult to get him to take food, as he seemed to have almost lost the power of deglutition. On the 17th the heart's action became very weak, though it was neither irregular nor intermittent, and the pulse varied from 99 to 110 , getting weaker and weaker, until it was imperceptible at the wrist, about an hour before death. At the time of admission the patient was free from thoracic disease. Two days before death he was again examined with the stethoscope, and no murmur was detected over the heart or aorta, but as there were loud mucous râles heard on auscultation over the lungs, it is very probable that a murmur was present, and escaped observation. Death took place on the 17th, being about seventy-two hours from the commencement of the last fainting attack, and a post-mortem examination was made forty-eight hours after death.

All the organs were examined, and traces of disease found in the brain. It will be sufficient, however, to give the appearances presented by the aorta, merely remarking that there was no sign of embolism in the cerebral vessels. On the removal of the lungs and heart attention was at once drawn to the aorta by its bright-red colour, which was so intense that the extent of the inflammation was seen without laying open the vessel. On dissecting the aorta downwards it was noticed that the redness gradually faded towards the bifurcation, and that half an inch or so beyond both iliacs had preserved their usual colour. On tracing the vessel upwards, the innominate, carotids, and subclavians showed the same bright hue, but it did not extend further than about an inch in the carotids and subclavians. All the vessels were laid open, when it was found that a fibrinous layer lined them to the same extent as the colour was seen externally. On running the finger over the surface, it was smooth in the direction of the blood current, but it felt slightly uneven when the finger was moved in the opposite direction. This layer could be peeled off without much difficulty ; it was about the thickness of paper, decidedly tough, and even when removed from the vessel had the same intensely red colour. It was thickest in the arch of the aorta, and extended to the very origin of the vessel in the left ventricle. The aortic valves were competent, and free from the least signs of disease. Neither in colour nor texture did they show the least trace of morbid action, and it was not a little strange to look upon these valves which had preserved their normal structure and function within touch of an acutely inflamed aorta. Here there was no gradual passage of diseased into healthy structure. The line of demarcation was abrupt and unmistakable. The endocardium was normal.

It is not easy to say whether the aortitis dated from the commencement of the last fainting attack. It could scarcely have existed long before that, as the patient was up and walking abont until suddenly struck down by the fit, which for the first twenty-four hours exactly resembled that noted eight days previously.

Bererley.

ACCORDING to a recent report of the Commissioner of Agriculture in Tennessee, Mr. Jez Killebraer, the consuners of tobacco on the face of the earth number not less than $800,000,000$. Probably more reliance can be reposed upon the figures this gentleman gives as to the production and commerce in tobacco in the United States. Thus, in 1560, he writes, the States produced over $430,000,000 \mathrm{lb}$. of tobacco, but ten years afterwards the yield of the plantations had fallen to $260,000,000 \mathrm{lb}$. The report does not give the rield of the tobacco crops in subsequent years, but it mentions that the exports of the herb alone in 1875 reached abcut $220,000,000 \mathrm{lb}$., valued at more than $25,000,000 \mathrm{dols}$. The value of the export of leaf tobacco in 1877 was $\$ g, 000,000$ dols.

\section{of atherror}

\section{HOSPITAL PRACTICE,}

\section{BRITISH AND FOREIGN.}

Nulla autem est alia pro eerto noscendi via, nisi quamplurimas et morborum et dissectionum historias, tum aliorum, tum proprias collectas habere, et

\section{LONDON HOSPITAL.}

ABSCESS OF THE LIVER, SEQUENTIAL TO DYSENTERY; ASPIRATION ; DEATH ; NECROPSY.

(Under the care of Drs. LANGDon Down and STEPHEN MACKENZIE.)

THE following notes should be read in conjunction with those of a case of abscess of the liver published in the Mirror of April 6th.

W. S - aged thirty-six, a waterman employed by the London and St. Katherine Dock Company at Gravesend. He had lived all his life at the riverside at Gravesend, and had spent the greater part of each day on the water. About seven years before admission he was laid up with what he called an " vlcerated stomach," by which he meant severe pain at the pit of the stomach, aggravated by food, especially if solid, relieved by the recumbent position. He did not remember that he vomited or passed blood by the stomach or bowels, or that he had diarrhoea. The pain gradually wore off, but the attack left him weak. With the exception of occasional colds, and dyspepsia if he took supper, he remained well until the summer of 1871. All through that summer he had pain in the abdomen, not localised, aggravated by taking food hurriedly, unattended with vomiting. He had every few days attacks of looseness of the bowels, but did not observe any blood in his stools at this time. About the middle of September of the same year the pain, which had been occasional, became continuous, and greatly increased in severity; it was localised at the pit of the stomach. Diarrhoea became more decided, blood and "slime and corruption" being noticed in his stools. Towards the end of September, and the beginning of October, the motions consisted of little more than blood and mucus. They were always passed with the greatest ease, and he had no tormina or tenesmus. In October he came under Dr. Fenwick's care, as an out-patient, for the dysenteric symptoms. These were relieved by the treatment employed, and the pain he had had all along ceased; but with the subsidence of the epigastric pain and diarrhcea, a new pain of a different character made its appearance in the right hypochondrium. About six weeks later he noticed a swelling in the situation of this pain-i. e., just below the margin of the right ribsand this gradually increased up to the time of admission. He stated positively that he had had no rigor throughout his illness, and that he had never once vomited. Several members of his family had suffered from "ulcerated stomach." He said the locality in which he lived at Gravesend was generally considered healthy, that diarrhoea was not common, and that his medical attendant had never known a case of dysentery to occur there.

He was admitted into the hospital on January 9th, 1872, under the care of Dr. Langdon Down. He was a sparely made man, with fair complexion, light-brown hair, and blue eyes. Cardiac dulness normal; heart-sounds healthy, but first sound and apex-beat exceedingly feeble. Percussion and auscultation of lungs normal. Liver dulness, bounded above by the lower margin of the fifth rib, extended about an inch below the costal arch. The lower part of the right chest was unduly prominent, having a convex surface about the size of a child's head; this was made more evident by the corresponding portion of the other side of the chest being retracted. The protrusion of the chest-wall commenced at the sixth rib, and extended to the margin of the ribs below. 'The intercostal spaces between these two points were almost obliterated. Springing from the lower part of this prominence was another smaller one, commencing at the lower border of the ribs, and extending two inches inwards from the mammary line. It projected above the surface sufficiently to be very obvious to the naked eye, and was about 
the size of a hen's egg. The skin covering it was red, and felt doughy, as though something were making its way to the surface. Fluctuation could be felt over the tumour. 'There appeared to be a portion of liver below the swelling, but this could not be accurately determined owing to tenderness at this point; elsewhere the abdomen was not tender. Splenic dulness not increased. No ascites; no oedema of the lower extremities; tongue slightly furred; appetite good; no nausea or vomiting. Bowels acted about three times a day; motions loose, but free from blood and mucus. All he suffered from was a burning, gnawing pain in the region of the swelling in the right hypochondrium, and he kept his hand over the part to protect it from the pressure of the bedclothes.

On Jan. 16th the skin was more red over the swelling. The largest needle of Dieulafoy's aspirator was introduced, and many ounces of reddish-brown or chocolate-coloured fiuid drawn off; the microscope showed this to consist of pus-corpuscles, compound granular corpuscles, and coloured blood-corpuscles. The aspiration caused no pain, and it afterwards afforded relief.

For several days after this there was no material change in the patient's condition, except an evening rise of temperature. He had pain in the region of the right hypohondrium. The abscess continued to discharge itself through the small opening made by the aspirator. Several ounces of dark-coloured matter escaped, which Dr. Fenwick found in part to consist of broken-down liver-cells. The skin around the opening was very thin and red on the 5th of February.

On Feb. 14th the aperture was enlarging, and the skin around sloughing.

On the 24 th the sinus almost admitted the little finger; the skin was sloughing for some distance around, and exthis it was red and cedematous. The patient had not suffered much pain at any time, only a gnawing feeling in the region of the liver. He had not vomited or shivered, but all along he had wasted and weakened, and been hectic. He was extremely feeble, his pulse soft and very compressowe. Bowels acted regularly; there was no diarrhoea, and tho appetite had been hitherto fair. The abscess discharged arge quantities of broken-down liver-substance; it had been washed out daily with lukewarm water.

Sloughing of skin went on uninterruptedly, and on Feb. 29th the necrosed skin was as large as the palms of two hands. What came from the abscess was now a dirty fetidlooking fluid. He wasted visibly, and was very weak. No vomiting, shivering, or purging. Patient gradually sank, and died March 2nd.

Neeropsy.-Body extremely wasted. There was a large saping wound in the right hypochondrium opening into peritoneal cavity. The heart was wasted, valves and - vrifiees healthy; left ventricle firmly contracted. Lobular pneumonia and odema of both lungs; base and posterior part of right lung covered with recent lymph. Spleen nommal. Liver: Upper surface of right lobe excavated by a large, ragged, irregular cavity, with sloughing walls. Left lobe had three masses of soft curdy matter not yet broken down into pus. Numerous smaller masses were scattered throughout substance of liver. The hepatic flexure of the colon was adherent to liver. A large sac, extending from whe lower part of thorax to the crest of ilium, outside peritomeum, but communicating with the general peritoneal cavity. The intercostal nerves lay in the sac dissected out, as by a scalpel. Stomach and small intestines healthy throughout. Large intestine, from ileo-creal valve to rectum, studded with ulcers, some circular, some transverse, some with solitary follicles, enlarged and surrounded by commencing ulceration. Coats of intestine much thickened. No pigmentation of mucous membrane. Kidneys normal.

Renarks by Dr. STEPHEN MACKENzIE. - The case was one of much interest. It is usually stated that abscess of the liver (so-called "tropical abscess") does not follow upon dysentery acquired in this and other temperate countries. Though rare, I have, however, seen more than one instance of this. The connexion between dysentery and abscess of the liver has given rise to much discussion. It is argued by some-Dr. Budd, for example-that it is due to purulent absorption from the intestine and deposition in the liver. Yet it is not, at least always, due to this occurrence. Morehead Tas collected twenty-one fatal cases of hepatic abscess withoutuleeration of intestine. Waring found that in 204 cases af hepatic abscess, fifty-one cases, or one quarter of the rhole number, were free from ulceration of intestine. At
Netley, also, of forty-eight fatal cases of tropical abscess, in thirty-four there was no intestinal lesion. Moreover, when they coexist, the abscess may precede the dysentery. It has been stated that something more than dysentery is required to produce the abscess; for when dysentery does occur in temperate climates abscess of the liver does not result. This statement the present case refutes. Dr. Baly stated that out of hundreds of cases of dysentery at Millbank prison, not one had abscess of the liver. The explanation of this is, that his cases of dysentery were of scorbutic origin. Abscess of the liver does follow dysentery of malariou origin in this country, as in the above case and others which I have seen. Sir Ranald Martin, Morehead, and Murchison are inclined to attribute the abscess to hepatitis, arising from exposure to cold. But in India, hepatitis and abscess of liver especially occur in hot low lying localities where malaria is endemic, and the range of malarious dysentery and hepatic abscess is almost identical. The evidence therefore seems to point to the malarious origin of the abscess of the liver. It may be that some particular form of malaria or some other coexisting circumstance, determines the occur rence of abscess ; for while it is common in India and Chine it is rare in the West Indies. In the present case aspiration was not attended with benefit; in others it is much more successful.

\section{NOTTINGHAM AND MIDLAND EYE} IN FIRMARY.

CASES OF MINERS' NYSTAGMUS.

(Under the care of Dr. BuLC TAYLOR.)

IT is important to remember that in the following cases Dr. Taylor states that there was no ametropia, and that the sight was good when the eyes were at rest.

CASE 1.-Benjamin W-, aged forty-four, a miner residing at Clay Cross, applied at the Eye Infirmary on Dec. $26 \mathrm{th}, 1877$. He stated that he had worked in a pit for thirty years, that his sight began to fail six months ago, and gradually got worse, so that he became unable to work. The eyeballs oscillated whenever he looked earnestly at any object. The oscillations were synchronous, horizontal, and equal in extent and number-namely, seventy-six in minute. He said he had not been accustomed during work to look upwards, but downwards, and that the dimness of vision was much aggravated by stooping. General health good; moderately temperate; does not smoke much. Ordered to give up working by artificial light, and to take small doses of steel and nux vomica thrice daily.

CASE 2.-J. H_-, aged twenty-nine, applied at the infirmary on Jan. 1st, 1878. Had worked at the Annesley pits twelve years. Three weeks ago he noticed that his Davy's lamp began to "dance" whenever he attempted work; said that it was often necessary for him to look upwards while at work, that he required to strain in order to see in the dim light of the pit, and that the defect was aggravated by stooping. In this case it was somewhat difficult to excite the oscillations, and they were not manifest until he had been shut up in the dimly-lighted ophthal. moscopic room and induced to stoop for ten minutes. It was then seen that the oscillations were both vertical and horizontal, causing a rotatory movement of the globes. They did not number more than fifty in a minute, and soon subsided. He attributed these favourable symptoms to his having had a "drop of drink," which he said had enabled him to master the disease. Is sometimes in temperate, and smokes moderately. Ordered to discontinue working in the pit, and to take bromide of potassium and tincture of nux vomica.

CASE 3. - James A- a - aged fifty-four, applied on Dec. 3rd, 1877. Had worked seventeen years at the Seymour pit, Stavely, and had had several blows on his head. In this case horizontal nystagmus was readily excited by directing the patient to look inwards. The oscillations numbered 100 in the minute. He said the disease had existed for a year, and was brought on by using a Clennie lamp, which flickers, and is consequently much worse for miners than the Davy lamp. He had not to look upwards while at work, and the disease was aggravated by stooping and exertion; fairly temperate, but smokes half an ounce daily. Ordered arsenic with steel and nux vomica thrice daily; to cease working underground and give up smoking. 